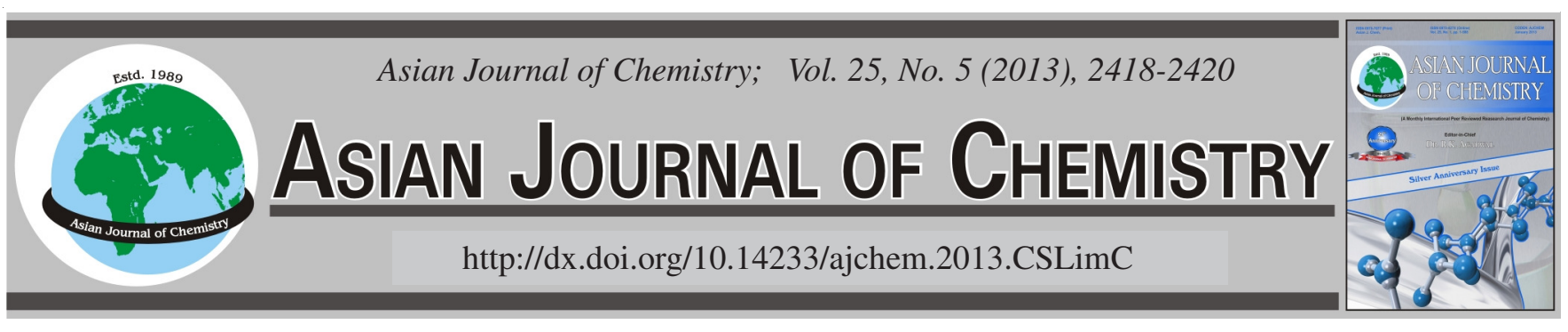

\title{
A Solvothermal Process to Synthesize Calcium Metastannate Nanoparticles Assisted by Microwave Irradiation
}

\author{
Chang Sung Lim
}

Department of Advanced Materials Science \& Engineering, Hanseo University, Seosan 356-706, South Korea

Corresponding author: Tel/Fax: +82 41 6601445; E-mail: cslim@ hanseo.ac.kr

Calcium metastannates $\left(\mathrm{CaSnO}_{3}\right)$ nanoparticles were synthesized successfully using a facile microwave solvothermal route followed by further heat-treatment. Well-crystallized $\mathrm{CaSnO}_{3}$ nanoparticles were formed after heat-treatment at $800{ }^{\circ} \mathrm{C}$ for $3 \mathrm{~h}$ showing a fine and homogeneous morphology with particle sizes of $20-40 \mathrm{~nm}$. The synthesized $\mathrm{CaSnO}_{3}$ nanoparticles were characterized by X-ray diffraction, Fourier transform infrared spectroscopy, scanning electron microscopy, energy-dispersive X-ray spectroscopy and transmission electron microscopy.

Key Words: Calcium metastannates, Microwave irradiation, Solvothermal process, Nanoparticles.

\section{INTRODUCTION}

Alkaline earth metal metastannates, with structures closely realated to the perovskite one, are of particular interest due to their unusual dielectric and semiconducting properties, leading to various applications such as thermally stable capacitors, ceramic dielectric bodies, gas and humidity sensors and battery electrode materials ${ }^{1-5}$. Numerous non-conventional soft chemical synthetic routes have been employed to synthesize alkaline earth metastannates by a range of processes, such as a solidstate reaction ${ }^{6}$, a co-precipitation method ${ }^{7}$, sol-gel $^{8}$, a combustion method ${ }^{9}$, a precursor route ${ }^{10,11}$, a microwave synthesis ${ }^{12}$, a polymerized complex method ${ }^{13}$, molten salt synthesis ${ }^{14}$, a pulsed laser deposition $^{15}$, a self-heat-sustained method ${ }^{16,17}$.

Generally conventional solid-state ceramic route was used for the preparation of metastannates based compounds. It requires prolonged calcinations at $c a .1200{ }^{\circ} \mathrm{C}$ for several hours along with intermediate processes in order to obtain reasonable phase purity. To coarse-grained powders synthesized using the conventional solid-state route has disadvantages of larger particle sizes, high temperature processing and lower phase purity. Microwave synthesis has the advantages of a very short reaction time, a small particle size, a narrow particle size distribution and is a high purity method for preparing polycrystalline samples. Microwave energy is delivered directly to the material through molecular interactions with an electromagnetic field ${ }^{18}$. Hydrothermal process is an efficient low temperature method that allows the formation of particles with high degree of crystallinity and easy dispersion in an aqueous medium. The use of microwave energy in hydrothermal system promotes the development of a rapid heating to the required temperature with rapid rates of crystallization ${ }^{19,20}$.

The microwave solvothermal process is adjusted to heat the metal metastannates uniformly resulting in fine particles with a controlled morphology and to fabricate the product in a green manner without the generation of solvent waste. Recently, microwave solvothermal processes have been reported the use of a facile and fast method in preparing nanocrystalline particles of metal tungstates with unique and enhanced properties $^{21,22}$. The solvothermal synthesis proceeds the reactions in a hot ethylene glycol solution as a polar solvent above a boiling point of $197^{\circ} \mathrm{C}$. When the microwave radiation is supplied to the ethylene glycol under a sealed pressure above boiling point, the components dissolving in the ethylene glycol are charged and vibrated in electric field interdependently.

In this study, the calcium metastannate $\left(\mathrm{CaSnO}_{3}\right)$ nanoparticles were synthesized using a facile solvothermal route assisted by the microwave irradiation. The characteristics of the synthesized calcium metastannate nanoparticles are discussed based on the microwave solvothermal reaction in ethylene glycol under the high sealed pressure. The synthesized $\mathrm{CaSnO}_{3}$ nanoparticles were characterized by X-ray diffraction, Fourier transform infrared spectroscopy, scanning electron microscopy and transmission electron microscopy. 


\section{EXPERIMENTAL}

Fig. 1 shows a flow chart for the synthesis of $\mathrm{CaSnO}_{3}$ nanoparticles by the cyclic microwave solvothermal process. $\mathrm{CaCl}_{2}$, $\mathrm{Na}_{2} \mathrm{SnO}_{3} \cdot 3 \mathrm{H}_{2} \mathrm{O}$ and ethylene glycol of analytic reagent grade were used to prepare the $\mathrm{CaSnO}_{3}$ compound. Each of 0.01 mol $\mathrm{CaCl}_{2}$ and $0.01 \mathrm{~mol} \mathrm{Na}_{2} \mathrm{SnO}_{3} \cdot 3 \mathrm{H}_{2} \mathrm{O}$ for $\mathrm{CaSnO}_{3}$ was dissolved in $30 \mathrm{~mL}$ ethylene glycol. The solutions were mixed and adjusted at a $\mathrm{pH} 9.5$ using $\mathrm{NaOH}$. The aqueous solution was stirred in ultrasonic bath at room temperature. In the sequence, the mixture was transferred into a Teflon lined digestion vessel of $120 \mathrm{~mL}$ capacity. The Teflon vessel was placed into a microwave solvothermal autoclave $(2.45 \mathrm{GHz}$, maximum power of $800 \mathrm{~W}$ ). The microwave solvothermal conditions were kept at $200{ }^{\circ} \mathrm{C}$ for $0.5 \mathrm{~h}$. After microwave solvothermal process, the microwave autoclave was cooled room temperature. The resulting solutions were treated with ultrasonic radiation and washed many times with distilled hot water. The white precipitates were corrected and dried at $100{ }^{\circ} \mathrm{C}$ in a dry oven. The final products were heat-treated at $800^{\circ} \mathrm{C}$ for $3 \mathrm{~h}$.

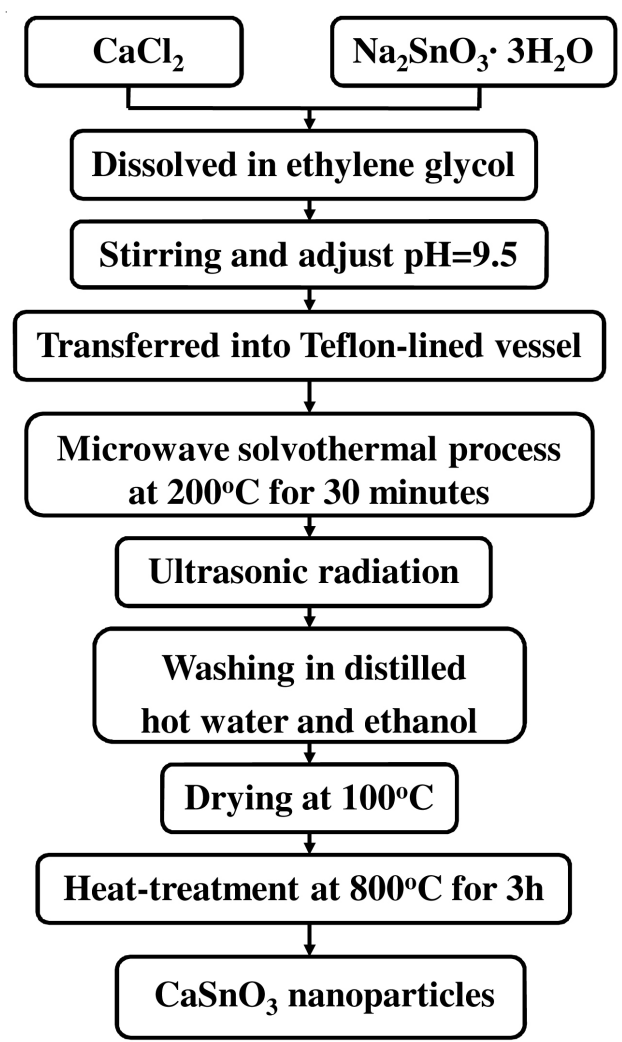

Fig. 1. Flow chart for the synthesis of calcium metastannate nanoparticles by the microwave solvothermal process

The existing phases of the calcium metastannate particles after the microwave solvothermal process were identified by powder XRD $\left(\mathrm{CuK}_{\alpha}\right.$, Rigaku D/MAX 2200, Japan). FTIR (Nicolet IR 200, Thermo Electron Corporation, USA) was used to examine the absorption behaviour of the synthesized $\mathrm{CaSnO}_{3}$ particles over the frequency range, $4000-400 \mathrm{~cm}^{-1}$. The microstructure, particle morphology/y and qualitative compositions of the $\mathrm{CaSnO}_{3}$ particles were observed by SEM (JSM-5600, JEOL, Japan) and TEM (JEM 2000-FX, 250 kV, Japan).

\section{RESULTS AND DISCUSSION}

Fig. 2 shows XRD patterns of the $\mathrm{CaSnO}_{3}$ nanoparticles synthesized by the microwave solvothermal process after heattreatment at $800^{\circ} \mathrm{C}$ for $3 \mathrm{~h}$. All XRD peaks could be assigned to a cubic structure of $\mathrm{CaSnO} 3$ (space group: $\mathrm{P} 22_{1} 2_{1} 2_{1}$, JCPDS 31-0312) $)^{10}$. It suggests that microwave solvothermal synthesis is suitable for the growth of $\mathrm{CaSnO}_{3}$ crystallites with the strongest major intensity peaks from the (020), (121) and (202) planes with some preferred orientation.

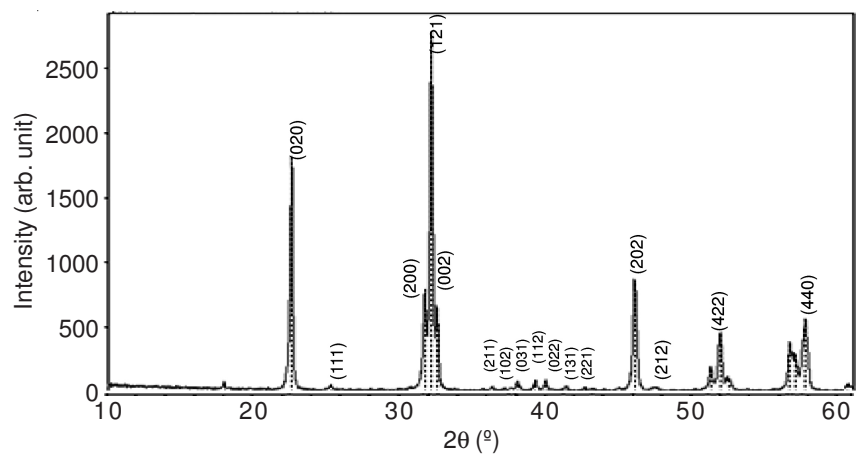

Fig. 2. XRD patterns of the $\mathrm{CaSnO}_{3}$ nanoparticles synthesized by the microwave solvothermal process

Fig. 3 shows FT-IR spectra of the $\mathrm{CaSnO}_{3}$ nanoparticles synthesized by the microwave solvothermal process in the wavenumber range, $4000-480 \mathrm{~cm}^{-1}$. The very strong absorbable peak at $629 \mathrm{~cm}^{-1}$ reveals typical characteristics of a strong $\mathrm{Sn}-\mathrm{O}$ stretching mode. The strong $\mathrm{Sn}-\mathrm{O}$ stretching modes are contributed to the uniform regular $\mathrm{SnO}_{6}$ octahedra of the metal stannates ${ }^{12}$. The bands at 856 and $1050 \mathrm{~cm}^{-1}$ are due to the presence of carbonates. The band at $1450 \mathrm{~cm}^{-1}$ is assumed that the samples prepared contain a small amount of surfaceadsorbed water and alcohol ${ }^{9}$.

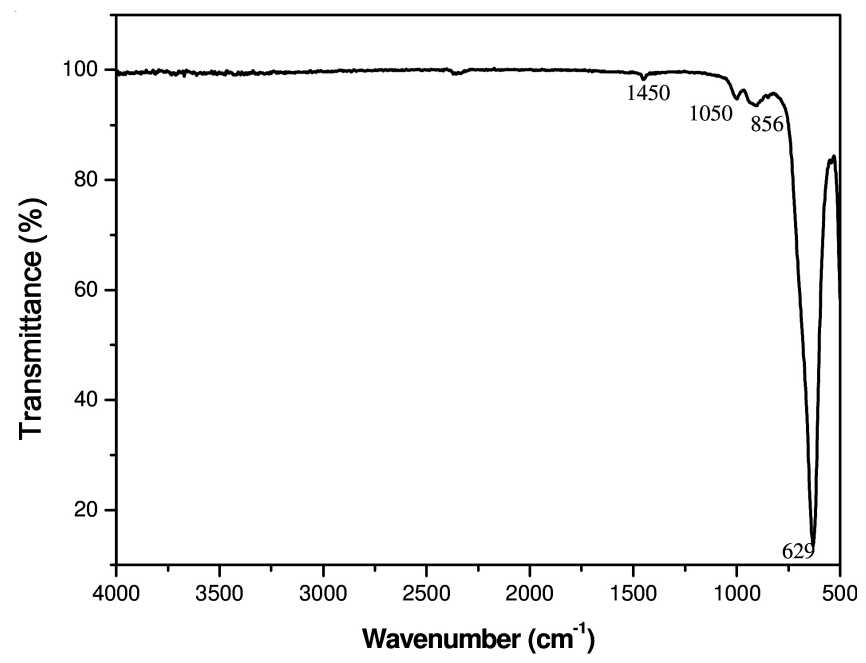

Fig. 3. FT-IR spectrum of the $\mathrm{CaSnO}_{3}$ nanoparticles synthesized by the microwave solvothermal process

Fig. 4 shows a SEM image (a) and a TEM image (b) of the $\mathrm{CaSnO}_{3}$ nanoparticles synthesized by the microwave solvothermal process. The SEM image of $\mathrm{CaSnO}_{3}$ in Fig. 4(a) shows a well-defined and homogeneous morphology, while the TEM image of $\mathrm{CaSnO}_{3}$ in Fig. 4(b) shows the particle sizes 

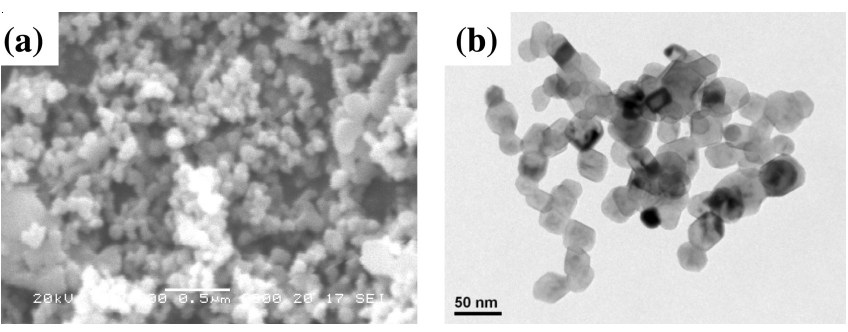

Fig. 4. A SEM image (a) and a TEM image (b) of the $\mathrm{CaSnO}_{3}$ nanoparticles synthesized by the microwave solvothermal process

of 20-40 $\mathrm{nm}$. The solvothermal synthesis proceeds the reactions between $\mathrm{CaCl}_{2}$ and $\mathrm{Na}_{2} \mathrm{SnO}_{3} \cdot 3 \mathrm{H}_{2} \mathrm{O}$ in a hot ethylene glycol solution as a polar solvent above a boiling point of $197^{\circ} \mathrm{C}$. The microwave solvothermal process of metal stannates occurs in accordance with the reaction:

$$
\mathrm{MCl}_{2} \cdot \mathrm{xH}_{2} \mathrm{O}+\mathrm{Na}_{2} \mathrm{SnO}_{3} \rightarrow \mathrm{MSnO}_{3}+2 \mathrm{NaCl}+\mathrm{xH}_{2} \mathrm{O}
$$

When the microwave radiation is supplied to the ethylene glycol under a sealed pressure above boiling point, the components dissolving in the ethylene glycol are charged and vibrated in electric field interdependently. The microwave solvothermal process is adjusted to heat the metal stannates uniformly resulting in fine particles with a controlled morphology and to fabricate the product in a green manner without the generation of solvent waste. The microwaveassisted solvothermal reaction involves the exchange of atomic/ ionic species, where the driving force is the exothermic reaction in ethylene glycol accompanying the formation of $\mathrm{NaCl}$ with a high lattice energy. The microwave exothermic reaction occurs so rapidly that the temperature and the pressure of the ethylene glycol increases so quickly that the reaction products are essentially heated up. The microwave-assisted solvothermal reactions provide a facile route for the synthesis of $\mathrm{CaSnO}_{3}$ nanoparticles, which were obtained in the form of loosely connected nano-sized particles at considerably lower temperatures with a high pressure than those usually employed for their synthesis. The well-defined $\mathrm{CaSnO}_{3}$ nanoparticles features synthesized by the microwave-assisted solvothermal process have a control over the morphology of the fine particles and can be used for technological applications.

\section{Conclusion}

Calcium metastannates nanoparticles were synthesized successfully by the microwave solvothermal processes between $\mathrm{CaCl}_{2}$ and $\mathrm{Na}_{2} \mathrm{SnO}_{3} \cdot 3 \mathrm{H}_{2} \mathrm{O}$ in a hot ethylene glycol solution as a polar solvent. The microwave solvothermal reactions occured so rapidly that the exothermic reaction was essentially used to heat up the metal metastannates. Well-crystallized $\mathrm{CaSnO}_{3}$ nanoparticles were formed after heat-treatment at $800{ }^{\circ} \mathrm{C}$ for $3 \mathrm{~h}$ showing a fine and homogeneous morphology with particle sizes of 20-40 nm. The very strong absorbable peak at 629 $\mathrm{cm}^{-1}$ was typical characteristics of a strong $\mathrm{Sn}-\mathrm{O}$ stretching mode.

\section{ACKNOWLEDGEMENTS}

This study was supported by Basic Science Research Program through the National Research Foundation of Korea (NRF) funded by the Ministry of Education, Science and Technology (2012-0007858).

\section{REFERENCES}

1. A. Kumar, R.N.P. Choudhary, B.P. Singh and A.K. Thakur, Ceram. Int., 32, 73 (2006).

2. A. Aydi, H. Khemakhem, A. Simon, D. Michau and R. von der Muehll, J. Alloys Comp., 484, 356 (2009).

3. W. Yude, S. Xiaodan, L. Yanfeng, Z. Zhenlai and W. Xinghui, Solid State Elect., 44, 2009 (2000).

4. A. Kumar, B.P. Singh, R.N.P. Choudhary and A.K. Thakur, J. Alloys Comp., 394, 292 (2005).

5. A.M. Azad, L.J. Min and M.A. Alim, Ceram. Int., 27, 335 (2001).

6. S. Upadhyay, O. Parkash and D. Kurmar, J. Mater. Sci. Lett., 16, 1330 (1997).

7. M.M. Rashad and H. El-Shall, Powder Technol., 183, 161 (2008).

8. A. M. Azad, M. Hashim, S. Baptist, A. Badri and A.U. Haq, J. Mater. Sci., 35, 5475 (2000).

9. A.S. Deepa, S. Vidya, P.C. Manu, S. Solomon, A. John and J.K. Thomas, J. Alloys Comp., 509, 1830 (2010).

10. C. Fan, X. Song, H. Yu, Z. Yin, H. Xu, G. Cao, D. Zheng and S. Sun, Mater. Lett., 61, 1591 (2007).

11. R. Koeferstein, L. Jaeger, M. Zenker and S.G. Ebbinghaus, J. Eur. Ceram. Soc., 29, 2324 (2009).

12. J. Bohnemann, R. Libanori, M.L. Moreira and E. Longo, Chem. Eng. J., 155, 905 (2009).

13. C.P. Udawatte, M. Kakihana and M. Yoshimura, Solid State Ionics, 128, 217 (2000).

14. B. Ramdas and R. Vijayaraghavan, Bull. Mater. Sci., 33, 75 (2010).

15. M.C.F. Alves, S. Boursicot, S. Ollivier, V. Bouquet, S. Deputier, A. Perrin, I.T. Weber, A.G. Souza, I.M.G. Santos and M. Guilloux-Viry, Thin Solid Films, 519, 614 (2010).

16. A.M. Azad, L.L.W.Shyan, T.Y. Pang and C.H. Nee, Ceram. Int., 26, 685 (2000).

17. A.M. Azad, L.L.W.Shyan and P.T. Yen, J. Alloys Comp., 282, 109 (1999).

18. S. Das, A.K. Mukhopadhyay, S. Datta and D. Basu, Bull. Mater. Sci., 32, 1 (2009).

19. K.P.F. Siqueira, R.L. Moreira, M. Valadares and A. Dias, J. Mater. Sci., 45, 6083 (2010).

20. J.C. Sczancoski, L.S. Cavalcante, M.R. Joya, J.a. Varela, P.S. Pizani and E. Longo, Chem. Eng. J., 140, 632 (2008).

21. J. Bi, L. Wu, Z. Li, Z. Ding, X. Wang and X. Fu, J. Alloys Comp., 480, 684 (2009).

22. T. Thongtem, A. Phuruangrant and S. Thongtom, Curr. Appl. Phys., 8, 189 (2008). 